Bajopas Volume 2 Number 1 June, 2009

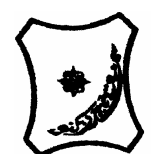

Bayero Journal of Pure and Applied Sciences, 2(1):132 - 134

Received: February, 2009

Accepted: May, 2009

\title{
SYNTHESIS AND CHARACTERIZATION OF IRON (II) AND NICKEL (II) SCHIFF BASE COMPLEXES
}

\author{
* Aliyu, H. N. and A. S. Mohammed \\ Department of Chemistry Bayero University, Kano, P. M. B. 3011, Kano, Nigeria, \\ *Correspondence author: hnuhu2000@yahoo.com
}

\begin{abstract}
The complexes of iron (II) and nickel (II) with schiff base derived from benzoin and 2-amino benzoic acid have been prepared. Solubility, melting point, decomposition temperature, conductance measurement, infrared (IR) and UV - Visible spectrophotometric studies were used in characterizing the compounds. The melting point of the schiff base determined is $120^{\circ} \mathrm{C}$. The decomposition temperatures of iron (II) and nickel (II) complexes are $152^{\circ} \mathrm{C}$ and $155^{\circ} \mathrm{C}$, while the molar conductance values are 11.2 and $10.7 \mathrm{ohm}^{-1} \mathrm{~cm}^{2} \mathrm{~mol}^{1}$, respectively. The UV-Visible spectrophotometric analysis revealed 1:1 (metal-ligand) stoichiometry for the two complexes.
\end{abstract}

Keywords: Schiff base, conductivity, azomethine, benzoin, spectrophotometry.

\section{INTRODUCTION}

When an aldehyde or a ketone is condensed with a primary amine, a Schiff base is produced, which is a compound containing azomethine group, $R-C=N-$ (Holm et al., 1966; Hobday and Smith, 1972). It has been known that a variety of metal ions on interaction with schiff bases yield chelates, for example; Holm et al. (1966) reported the synthesis and magnetic studies on schiff base complexes of copper (II). Recently, Xishi et al. (2003) reported the synthesis and characterization of Mn (II), Co (II) and Cu (II) complexes with a novel schiff base ligand derived from 2, 2' - bis(pmethoxylphenylamine) and salicylic aldehyde. Transition metal schiff base complexes have been found to play a vital role in medicine, biological systems and industries. The field of medicine has witnessed an increase in the number of complexes with therapeutic value, for example, cobalt (III) schiff base complexes are potential antiviral agents, cisdichlorodiamineplatinum (II) is an anti-cancer agent and copper (II) schiff base complex is an antitubercular agent (Lippard, 1994; Bleomink and Reedi, 1996). The use of atom transfer radical cyclisation mediated by copper (II) schiff base complexes to furnish nitrogen heterocycles most of which are biologically active molecules and also the use of copper schiff base catalyst in carbon based radical cyclisation reactions were recently investigated (Clerk and Jones, 1989; Clerk et al., 1998; Clerk et al., 1999). The complex compound formed by schiff base derived from benzoin and 2-amino benzoic acid with cobalt (II) salt has been reported (Mahaptra et al.., 1977). This paper reports the preparation and characterization of two new complex compounds formed by iron (II) and nickel (II) metal ions with the schiff base.

\section{MATERIALS AND METHODS}

The solvents and chemicals used in this work were of Analar grade. All the glass wares used were washed thoroughly with distilled water and dried in an oven. Weighing was carried out on electric metler balance, model $A B$ 54. Melting point, decomposition temperature and coordinated water were determined on Gallenkamp melting point apparatus. Infrared spectral analyses were recorded using Fourier Transformed IR, Genesis series model in Nujol within $400-4000 \mathrm{~cm}^{-1}$. Electrical conductivity measurements were carried out using conductivity meter model Jenway 4010, while UV- visible spectral measurements were done on a Pye Unicam UV-visible spcetrophotometer.

\section{Preparation of Benzoin}

Into a $500 \mathrm{~cm}^{3}$ round bottom flask was added $65 \mathrm{~cm}^{3}$ of rectified spirit, $47.5 \mathrm{~cm}^{3}$ of benzaldehyde and a solution of $5 \mathrm{~g}$ of sodium cyanide in $50 \mathrm{~cm}^{3}$ of water. A condenser was then attached and the mixture refluxed on a steam bath for half an hour. The flask and its contents were cooled in an ice-bath to precipitate pale yellow crystals, which were suction filtered, washed with cold water, dried and then recrystallized from $40 \mathrm{~cm}^{3}$ of hot rectified spirit (Mahaptra et al., 1977).

\section{Preparation of the Schiff Base Ligand}

Into an ethanolic solution of the prepared benzoin $(0.01 \mathrm{~mol})$ and 2 -amino benzoic acid $(0.01 \mathrm{~mol})$ in a $500 \mathrm{~cm}^{3}$ round bottom flask, $3.0 \mathrm{~g}$ of anhydrous sodium acetate was added. The mixture was refluxed for an hour on a steam bath. To precipitate the grayish white product, the content was poured into an ice-cold water which was separated and recrystallized from rectified spirit, suction filtered, washed with water, and dried in a vacuum dessiccator (Mahaptra et al.., 1977). 


\section{Preparation of the Complexes}

Ethanolic solutions of metal chloride $(0.025 \mathrm{~mol})$ and schiff base $(0.05 \mathrm{~mol})$ were mixed and the resulting mixture followed by dropwise addition of ammonia until the metal chelate separated, which were then suction filtered, washed with ethanol and ether before dried in vacuum dessicator. The crystals were recrystallized from rectified sprit and dried (Mahaptra et al., 1977).

\section{RESULTS AND DISCUSSION}

The benzoin and Schiff base have been prepared as reported (Mahaptra, et al.,1977; Vogel, 1978), they are pale yellow and grayish white, respectively. The iron (II) and nickel (II) Schiff base complexes have been prepared using the adopted synthetic procedure reported by Mahaptra, et al. (1977), the compounds are brown and blue, respectively. The melting point temperatures of the benzoin and the schiff base are $137^{\circ} \mathrm{C}$ and $120^{\circ} \mathrm{C}$, respectively, which are in agreement with the literature values (Vogel, 1978; Mahaptra, et al., 1977). The decomposition temperatures of iron (II) and nickel (II) Schiff base complexes are $152^{\circ} \mathrm{C}$ and $155^{\circ} \mathrm{C}$, respectively, which present fairly stable complex compounds. The percentage by weight (Table 1 ) of iron and nickel in the complexes are 12.60 and 12.90 , respectively, and these revealed 1:1 metal to ligand ratio. The coordinated water analysis (Table 2) of the complexes indicated three water molecules per molecular formula, which is in complete agreement with the report on cobalt (II) schiff base complex (Mahaptra et al., 1977). The complexes are insoluble in water and common organic solvents, but are readily soluble in dimethylsulphoxide (DMSO). The molar conductance values (Table 3 ) of iron (II) and nickel (II) schiff base complexes in $1 \times 10^{-3} \mathrm{M}$ DMSO solution were 11.2 and $10.7 \mathrm{ohm}^{-1} \mathrm{~cm}^{2} \mathrm{~mol}^{-1}$, respectively, suggesting their non-ionic nature (Geary, 1971). The IR spectrum (Table 4) of the free schiff base shows bands of medium intensity at 1210,1590 , and $1670 \mathrm{~cm}^{-1}$ which are for $(\mathrm{C}-\mathrm{O}), \quad(\mathrm{C}=\mathrm{N})$ and $\quad(\mathrm{C}=\mathrm{O})$, respectively (Silverstein and Bassler 1967; Freedman, 1961; Nakamato, 1963). The same three bands were also noticed in the two complexes, which confirmed coordination of the Schiff base to the respective metal ions. The bands in the regions $511-558 \mathrm{~cm}^{-1}$ and 470 $478 \mathrm{~cm}^{-1}$ are assigned to $(\mathrm{M}-\mathrm{N})$ and $(\mathrm{M}-\mathrm{O})$ stretching vibrations, respectively (Mahaptra et al., 1977), confirming coordination of the schiff base to the metal ions. The broad bands in the region 3350$3355 \mathrm{~cm}^{-1}$ observed in the two complexes have been established to be hydrated due to the broad bands in the region 3350-3355 $\mathrm{cm}^{-1}$ (Patel and Agwara, 1990). The coordinated water analysis of the complexes indicated three water molecules per molecular formula, which is in complete agreement with the report on cobalt (II) schiff base complex (Mahaptra et al., 1977).

The spectrophotometric analysis (Table 4) revealed 1:1 (metal-ligand) stoichiometry in the two complex compounds, which is common feature in the first row transition metals (Holm and O'Connon, 1971; Mahaptra et al., 1977). Therefore, from the analyses carried out in this work, the proposed general molecular structure of iron (II) and nickel (II) schiff base complexes is as presented below;

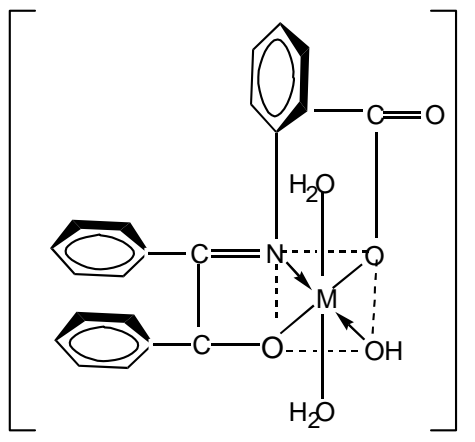

Figure 1: The proposed general Structure of iron (II) and nickel (II) Schiff base complexes.

Table 1: Percentage Composition by Weight of Metal in the Complex

\begin{tabular}{cccc}
\hline S/No. & Compound & \%Metal Calculated & \%Metal Observed \\
\hline 1 & {$\left[\mathrm{FeL}\left(\mathrm{H}_{2} \mathrm{O}\right)_{3}\right]$} & 12.49 & 12.60 \\
2 & {$\left[\mathrm{NiL}\left(\mathrm{H}_{2} \mathrm{O}\right)_{3}\right]$} & 13.23 & 12.90 \\
\hline
\end{tabular}

Table 2: Percentage Composition by Weight of Water in the Complexes

\begin{tabular}{cccc}
\hline S/No. & Compound & \%Water Calculated & \% Water Observed \\
\hline 1 & {$\left[\mathrm{FeL}\left(\mathrm{H}_{2} \mathrm{O}\right)_{3}\right]$} & 12.25 & 11.19 \\
2 & {$\left[\mathrm{NiL}\left(\mathrm{H}_{2} \mathrm{O}\right)_{3}\right]$} & 12.17 & 12.12 \\
\hline
\end{tabular}


Bajopas Volume 2 Number 1 June, 2009

Table 3: Conductivity Measurement of the Complexes in DMSO $\left(1 \times 10^{-3} \mathrm{M}\right)$

\begin{tabular}{cccc} 
S/No. & Compound & Specific Conductance (k) & $\begin{array}{c}\text { Molar Conductance } \\
\left(\mathbf{O h m}^{-\mathbf{1}} \mathbf{c m}^{\mathbf{2}} \mathbf{m o l}^{\mathbf{- 1}} \mathbf{)}\right.\end{array}$ \\
\hline 1 & {$\left[\mathrm{FeL}\left(\mathrm{H}_{2} \mathrm{O}\right)_{3}\right]$} & $9.8 \times 10^{-6}$ & 11.20 \\
2 & {$\left[\mathrm{NiL}\left(\mathrm{H}_{2} \mathrm{O}\right)_{3}\right]$} & $9.3 \times 10^{-6}$ & 10.70 \\
\hline
\end{tabular}

\begin{tabular}{|c|c|c|c|c|c|c|}
\hline S/No. & Compound & $\begin{array}{l}V(C=N) \\
\left(\mathrm{cm}^{-1}\right)\end{array}$ & $\begin{array}{l}v(\mathrm{C}-\mathrm{O}) \\
\left(\mathrm{cm}^{-1}\right)\end{array}$ & $\begin{array}{l}(\mathrm{O}-\mathrm{H}) \\
\left(\mathrm{cm}^{-1}\right)\end{array}$ & $\begin{array}{l}V(M-N) \\
\left(\mathrm{cm}^{-1}\right)\end{array}$ & $\begin{array}{l}V(\mathrm{M}-0) \\
\left(\mathrm{cm}^{-1}\right)\end{array}$ \\
\hline 1 & Schiff Base & 1590 & 1210 & - & - & - \\
\hline 2 & {$\left[\mathrm{FeL}\left(\mathrm{H}_{2} \mathrm{O}\right)_{3}\right]$} & 1595 & 1208 & 3350 & 511 & 470 \\
\hline 3 & {$\left[\mathrm{NiL}\left(\mathrm{H}_{2} \mathrm{O}\right)_{3}\right]$} & 1596 & 1279 & 3355 & 558 & 467 \\
\hline
\end{tabular}

\section{REFERENCES}

Bleomink, M. J., and Reedi, J. K., (1996); "Metal Ions in Biological Systems", $3^{\text {rd }}$ Edition, Mercel Dekker Inc. New York, pp. 641-644.

Clerk, A. J. and Jones, K., (1989); "Evidence on the Nature of Cobalt-mediated Aryl- radical Cyclization", Tetrahedral Letters, 30: 54855489.

Clerk A. J., Duncalf R. P., Filik R. P., Thomas G. H., and Wongtap H., (1999); "N-Alkyl- 2pyridylmethanimines as Tuneable Alternatives to Bipyridine Ligan in Copper Medicated Atom Transfer Radical Cyclization Reactions", Tetrahedron Letters, 1: 3807-3812.

Clerk, A. J., Filik, R. P., Thomas, G. H., and Wongtap, H., (1998); "Generation and Cyclization of Homogeneous and Solid Supported Copper (II) Schiff Base Complexes", Journal American Chemical Society, 1: 216, 743.

Freedman, H. H., (1961), "Spectroscopic Study of the Hydrogen Bond Between Hydroxyl and Nitrogen", Journal of the American Chemical Society, 83: 2900-2904.

Geary, W. J., (1971), "The Use of Conductivity Measurement in Organic Solvents for the Characterization of Coordination Compounds", Coordination Chemistry Review, 7: 82-110.

Hobday, M. D. and Smith, T. D., (1972); "N, N'ethylene bis(salicylideneiminato) Transition Metal ion Chelates", Coordination Chemistry Review, 9: 311-337.

Holm, R. and O'Connon, M. J. (1971); "The Steterochemistry of Bischelate Metal (II)
Complexes", Progressive Inorganic Chemistry, 14:241-401

Holm, R. H., Everett, J. R., and Chakravorty, R. S., (1966); "Metal Complexes of Schiff Bases and $\beta$-ketoimines", Inorganic Chemistry, 7: 83214.

Lippard, S. J., (1994); "Bioinorganic Chemistry", $2^{\text {nd }}$ Edition, University Science Books Millvalley, pp. 505-508.

Mahaptra, B. B., Mahaptra, B. K., and Guru, S., (1977);"Complex of Cobalt (II) with Tridentate Schiff Base", Journal of Inorganic and Nuclear Chemistry, 39: 2291-2292.

Nakomato, K., \{1963); "Infrared Spectra of Inorganic and Coordination Compounds", Willey, New York, pp. 234-241.

Patel, K. S. and Agwara, M. O., (1990); "Hexamethylenetetramine Complexes of Divalent Metal Nitrates", Nigerian Journal of Science, 24: 107.

Silverstein, S. M. and Bassler, G. C., (1967); "Spectrophotometric Identification of Organic Compounds", Willey, New York, pp. 12-23.

Vogel, A. I., (1978); "Practical Organic Chemistry", $4^{\text {th }}$ Edition Longman Group Limited, London, pp.806-809.

Xishi, T., Xian, H. Y., Qiang, C. and Minyu, T., (2003), "Synthesis of Some Transition Metal Complexes of a Novel Schiff Base Ligand Derived from 2, 2' - Bis(p-Methoxy Phenylamine) and Salicylic Aldehyde", Molecules, 8: 439-443. 